\title{
Two Celebrated Classical Problems in Geometric Constructions
}

\author{
Dua Masalah Klasik Terkenal di Dalam Konstruksi Geometri \\ Saiful Amri, Radhiah*
}

\begin{abstract}
The main topic of this paper is about two celebrated classical problems in geometric constructions where the only allowed instruments are compass and ruler with no scale. Two such problems are (1) trisecting an angle, and (2) doubling the cube. In addition, we also study about the construction of 7gon and 10-gon.
\end{abstract}

Key Words: Geometric construction, trisecting an angle, doubling the cube,7-gon, 10-gon

\begin{abstract}
ABSTRAK
Inti tulisan ini adalah membahas dua masalah klasik yang sangat terkenal dalam lukisan geometri dimana alat yang diperbolehkan hanya jangka dan mistar tanpa skala. Kedua masalah tersebut adalah (1) membagi tiga sebuah sudut, dan (2) menggandakan volume kubus. Selain itu, tulisan ini juga membahas tentang keterlukisan dari segi-7 dan segi-10 beraturan.
\end{abstract}

Kata kunci: Lukisan geometri, membagi 3 sebuah sudut, menggandakan volume kubus, segi-7, segi-10

\section{Pendahuluan}

Lukisan geometri adalah suatu topik yang dipelajari sejak lama, bahkan topik tersebut sudah dikenal sejak sebelum masehi. Ada berbagai jenis lukisan geometri, perbedaan jenisnya terletak pada alat yang digunakan. Jenis yang cukup populer adalah lukisan geometri yang hanya menggunakan jangka dan mistar tanpa skala. Dalam tulisan ini, selalu diasumsikan bahwa alat yang digunakan hanya berupa jangka dan mistar tanpa skala.

Melukis segi- $n$ (beraturan) telah menjadi topik yang sangat disukai. Sejak jamannya Pythagoras, lukisan untuk segi- $n$ telah diketahui untuk $n=3,4,5,6$. Namun untuk segi-7, mereka tidak tahu cara melukisnya hingga berabad-abad sampai akhirnya pada tahun 1801 
Gauss membuktikan bahwa segi- $n$ dapat dilukis jika dan hanya jika $n=2^{k} p 1 p 2 \ldots p r$, dengan $p$ prim berbeda yang berbentuk $2^{2^{s}}+1$ dan $k, s \in \mathbb{N} \stackrel{\text { def }}{=}\{0,1,2, \ldots\}$ (Martin, 1991). Secara khusus, Gauss membuktikan bahwa segi-7 tidak dapat dilukis.

Selain segi-7, dua masalah kuno lain yang cukup terkenal dan merupakan inti dari tulisan ini adalah:

P1 : (Trisecting an Angle) Diberikasudut $\alpha$, dapatkah dilukis sudut $\frac{1}{3} \alpha$ ?

P2: (Doubling the Cube) Diberikan suatu kubus, dapatkah dilukis kubus baru yang memiliki volume dua kali kubus semula?

Ada banyak kasus dimana (P1) terselesaikan, misalnya untuk $\alpha=90^{\circ}$, jadi konteks (P1) yang dimaksud adalah secara umum. Pada tahun 1837 matematikawan Perancis Pierre Wantzel (1814-1848) membuktikan suatu dalil tentang lapangan yang sekaligus menjawab kedua pertanyaan (P1) dan (P2) (Martin, 1991). Wantzel membuktikan bahwa sudut $20^{\circ}$ tidak dapat dilukis dengan memanfaatkan dalil tersebut, sehingga sudut $60^{\circ}$ tidak dapat dibagi tiga. Jadi, tidak ada metode untuk membagi sudut dalam tiga bagian. Wantzel membuktikan pula bahwa $\sqrt[3]{2}$ tidak dapat dilukis dengan memanfaatkan dalil yang sama, yaitu kubus satuan tidak dapat digandakan volumenya. Ini memberikan jawaban untuk pertanyaan $(\mathrm{P} 2)$.

\section{Tujuan Penulisan}

Penulisan artikel iniuntuk menjawab dua hal, yaitu

1. Jika diberikan sudut $\alpha$, dapatkah dilukis sudut $\frac{1}{3} \alpha$ ?

2. Diberikan suatu kubus, dapatkah dilukis kubus baru yang memiliki volume dua kali kubus semula?

3. Keterlukisan segi-7 dan dan segi-10

\section{Pembahasan}

\section{Lapangan Bilangan Terlukis}

Dalam melukis garis, satuan yang digunakan adalah sembarang bilangan riil positif namun harus ditetapkan terlebih dahulu, dalam tulisan ini digunakan satuan 1 tanpa mengindahkan satuan panjangnya. Tentu saja diasumsikan garis dengan panjang 1 dapat dilukis. 


\section{Saiful Amri, Radhiah}

Definition 1. Bilangan riil $a \neq 0$ dikatakan dapat dilukis bila garis dengan panjang $|a|$ dapat dilukis. Himpunan bilangan yang dapat dilukis dinotasikan dengan $\mathbb{L}$ dan sebagai tambahan diasumsikan $0 \in \mathbb{L}$

Dalil 2. Misal $a, b \in \mathbb{L}$. Maka $a+b, a b \in \mathbb{L} ; j i k a b \neq 0$, maka $a / b \in \mathbb{L}$.

\section{Bukti}

Menunjukkan $a+b \in \mathbb{L}$ adalah trivial. Untuk menunjukkan $a b$ dan $a / b$ di $\mathbb{L}$, tidak masalah dengan mengasumsikan $a b \in \mathbb{R}^{+}$. Dibuat sembarang garis $l$ dan $k$ yang tidak sejajar dan berpotongan pada titik $P$. Dibuat pula titik $A \in l$ dan $B, S \in k$ sehingga $a=\overline{P A}$, $b=\overline{P B}, \overline{P S}=1$. Tidak sulit melukis titik $C \in l$ sehingga $S A \| B C$. Karena $\triangle P S A \approx \triangle P B C$, maka $\overline{P B}: \overline{P C}=\overline{P S}: \overline{P A}$, jadi $a b=\overline{P A} \times \overline{P B}=\overline{P C} \times \overline{P S}=\overline{P C}$ terlukiskan.
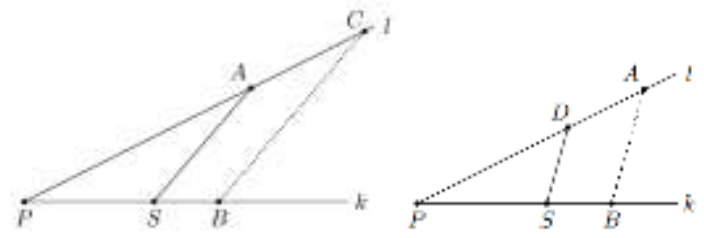

Gambar 1. Ilustrasi $a b$ dan $a / b$ berada di $\mathbb{L}$

Untuk membuktikan $a / b \in \mathbb{L}$, misal $P, A, B, S, k, l$ seperti sebelumnya. Lukis $D \in l$ sehingga $S D \| B A$. Karena $\triangle P S D \approx \triangle P B A$ maka $a / b=\overline{P A}: \overline{P B}=\overline{P D}: \overline{P S}=\overline{P D}$, jadi $a / b \in \mathbb{L}$.

Dalil 2 mengatakan bahwa $\mathbb{L}$ berupa sublapangan dari $\mathbb{R}$ yang memuat $\mathbb{Q}$. Lapangan $\mathbb{L}$ lebih luas dari $\mathbb{Q}$ sebab ada bilangan irrasional yang berada di $\mathbb{L}$, misalnya $\sqrt{2}$.

Dalil 3. Jika $a \in \mathbb{L}$ maka $\sqrt{a} \in \mathbb{L}$.

Bukti. Buat titik $A, P, B$ pada satu garis dimana $\overline{A P}=1$ dan $\overline{P B}=a$. Lukis titik tengah $O$ dari $\overline{A B}$ dan $Q \in \odot\left(O ; \frac{1+a}{2}\right)$ sehingga $Q P \perp A B$. Karena $\angle A Q B=90^{\circ}$ maka $\triangle A Q B \approx$ $\triangle A P Q \approx \triangle Q P B$ dan dari $\triangle A P Q \approx \triangle Q P B$ didapat $\overline{P Q} \div \overline{A P}=\overline{P B} \div \overline{Q P}$, jadi $\sqrt{a}=$ $\sqrt{\overline{A P} \times \overline{P B}}=\sqrt{\overline{P Q} \times \overline{Q P}}=\overline{P Q}$ terlukiskan. 
Misal $F$ lapangan. Lapangan $K$ disebut perluasan dari $F$ bila $F \leq K$. Lapangan $K$ bisa dipandang sebagai ruang vektor atas $F$ (dengan perkalian skalar berupa perkalian pada $K$ ) dan dalam hal ini $\operatorname{dim}_{\mathrm{F}}(K)$ ditulis dengan $[K: F]$ dan disebut sebagai derajat dari $K$ terhadap F. Dapat dibuktikan namun panjang (detailnya lihat Herstein (1999)) bahwa:

Dalil 4. Jika $L \supset K \supset F$ barisan dari sublapangan dengan $[L: K]$ dan $[K: F]$ berhingga $\operatorname{maka}[L: F]=[L: K][K: F]$

Definisi 5. Misal $F$ lapangan dan $K$ perluasan dari $F$. Unsur a $\in K$ dikatakan aljabar terhadap $F$ bila ada $p(x) \in F[x]^{\times} \stackrel{\text { def }}{=} F[x] \backslash\{0\}$ sehingga, $p(a)=0$; bila sebaliknya, $a$ disebut transenden (terhadap $F$ ).

Jika $a$ aljabar terhadap $F$ maka ada polinom berderajat terkecil $p(x)$ di $F[x]^{\times}$sehingga $p(a)=0$ polinom ini disebut polinom minimal untuk $a$ terhadap $F$. polinom minimal harus tak tereduksi seperti yang ditegaskan oleh:

Dalil 6. Misal $K$ perluasan dari $F$. Jika $a \in K$ aljabar terhadap $F$ maka polinom minimalnya tak tereduksi.

Bukti. Jika polinom minimal $p(x)$ tereduksi maka $p(x)=g(x) h(x)$ untuk suatu $g, h \in$ $F[x]$ yang tak-konstan. Karena $K$ tak-punya pembagi nol dan $0=p(a)=g(a) h(a)$ maka $g(a)=0$ atau $h(a)=0$; sebutlah $g(a)=0$. Maka menurut pemilihan $p$ tentu $\operatorname{deg} p \leq \operatorname{deg} g$, padahal $\operatorname{deg} p>\operatorname{deg} g$.

Sifat berikutnya yang juga dapat dibuktikan adalah

Dalil 7. Misal $K$ perluasan dari $F$ dan $a \in K$ aljabar terhadap $F$ dengan $p(x)$ adalah polinom minimalnya. Maka

$$
F[a] \stackrel{\text { def }}{=}\{f(a): f(x) \in F[x]\}
$$

berupa lapangan yang merupakan perluasan dari $F$ dan $[F[a]: F]=\operatorname{deg} p \square$

Misal $F$ sublapangan dari $\mathbb{L}$. Titik $(x, y) \in \mathbb{R}^{2}$. dikatakan pada bidang $F$ bila $x, y \in F$. Suatu garis dikatakan pada bidang $\mathrm{F}$ bila ada dua titik $(a, b) \neq(c, d)$ pada bidang $F$ yang terletak pada garis itu. Suatu lingkaran dikatakan pada bidang $F$ bila jari-jarinya di $F$ dan titik pusatnya pada bidang $F$. Maka garis dan lingkaran pada bidang $F$ berbentuk

$$
\begin{gathered}
y=a x+b, \\
x^{2}+y^{2}+d x+e y+f=0
\end{gathered}
$$

$\operatorname{dimana} a, b, d, e, f \in F \subset \mathbb{R}$ 


\section{Saiful Amri, Radhiah}

Dalam lukisan geometri yang menggunakan mistar dan jangka, saat menggunakan mistar tak lain adalah membuat penggal garis yang melalui dua titik pada bidang $F$. Menggunakan jangka tak lain membuat penggal lingkaran dengan pusatnya berada pada bidang $F$ dan jarijarinya di $F$.

Suatu masalah lukisan dapat dipecahkan bila dapat dilukis titik-titik baru sehingga masalah tersebut terselesaikan. Sebagai contoh untuk melukis sudut $60^{\circ}$, buat garis yang melalui $O=(0,0)$ dan $P=(1,0)$ pada bidang $\mathbb{Q}$. Lalu buat $\odot c_{1}=(0 ; 1)$ dan $\odot c_{2}=$ $(P ; 1)$. Maka diperoleh titik baru $Q \in c_{1} \cap c_{2}$. Karena $\triangle Q O P$ sama sisi, $\angle Q O P=60^{\circ}$, terlukiskan.

Secara umum, diberikan sembarang masalah lukisan, berarti diberikan sejumlah titik pada bidang $F$, dimana $F$ suatu sublapangan dari $\mathbb{L}$. Selanjutnya cari titik-titik baru untuk menyelesaikan masalah tersebut. Titik-titik baru itu didapatkan melalui tiga kemungkinan berikut:

(1) Perpotongan antara dua garis pada bidang $F$

(2) Perpotongan antara garis dan lingkaran pada bidang $F$ atau

(3) Perpotongan antara dua lingkaran pada bidang $F$

Pada kasus (1), jika dua garis $y=a x+b$ dan $y=c x+d$ pada bidang $F$ berpotongan maka $a \neq c$ dengan titik potong $P=\left(x_{0}, a x_{0}+b\right)$ dimana $x_{0}=\frac{d-b}{a-c}$. Titik $P$ ini pada bidang $F$ sebab $F$ lapangan dan $a-c \neq 0$.

Pada kasus (2), misal $y=a x+b$ dan $x^{2}+y^{2}+c x+d y+e=0$ adalah garis dan lingkaran pada bidang $F$. Subtitusi $y=a x+b$ ke persamaan lingkaran akan didapatkan sebuah persamaan kuadrat berbentuk $x^{2}+s x+t=0$ untuk suatu $s, t \in F$ yang memiliki akar

$$
x^{\prime}=\frac{-s \pm \sqrt{D}}{2}
$$

dimana $D=s^{2}-4 t$. Jika $D<0$ maka garis dan lingkaran tidak berpotongan.

Misal $D \geq 0$. Maka garis dan lingkaran berpotongan di $P=\left(x^{\prime}, a x^{\prime}+b\right)$. Jika $\sqrt{D} \in F$ maka $P \in F$; jika $\sqrt{D} \notin F$ maka $P \in F[\sqrt{D}]$ dan menurut Dalil 3 tentu $\sqrt{D} \in \mathbb{L}$. Jadi $P$ selalu di $\mathbb{L}$ dan $[F[\sqrt{D}]: F]=1$ atau $=2$.

Kasus terakhir, untuk menentukan titik potong dua lingkaran

$$
x^{2}+y^{2}+a x+b y+c=0 \text { dan }
$$




$$
x^{2}+y^{2}+d x+e y+f=0
$$

pada bidang $F$, dengan mengurangkan kedua persamaan itu diperoleh

$$
(a-d) x+(b-e) y+(c-f)=0
$$

yang berupa garis pada bidang F. Ini kembali lagi menjadi masalah menentukan titik potong antara lingkaran dan garis yang baru saja dibahas pada kasus 2 .

Ketiga kasus itu menyimpulkan satu hal bahwa jika garis dan garis atau garis dan lingkaran atau lingkaran dan lingkaran pada bidang $F$ berpotongan, maka titik potongnya berada pada bidang $F$ atau bidang $F[\sqrt{a}]$ untuk suatu $a \in F$ dan $F[\sqrt{a}] \leq \mathbb{L}$. Jika $\sqrt{\mathrm{a}} \in \mathrm{F}$ maka $F[\sqrt{a}]=F$, jadi $[F[\sqrt{a}]: F]=1$. Jika $\sqrt{a} \notin \mathrm{F}$ maka $p(x)=x^{2}-a \in F[x]$ berupa polinom minimal untuk $\sqrt{a}$ terhadap $F$ dan dari Dalil 7 diperoleh $[F[\sqrt{a}]: F]=2$. Perluasan $F[\sqrt{a}]$ disebut juga perluasan kuadratik dari $F$.

Dalil 8. Jika a $\in \mathbb{L}$ maka $[\mathbb{Q}[a]: \mathbb{Q}]=2^{m}$ untuk suatu $m \in \mathbb{N}$

\section{Bukti}

Untuk melukis $a$ mulai dari bidang $F_{0}=\mathbb{Q}$ Jika $a \notin F_{0}$ maka dilanjutkan ke bidang $F_{1}$ yang merupakan perluasan kuadratik dari $F_{0}$. Jika $a \notin F_{1}$, perlu dilanjutkan ke $F_{2}$, dan seterusnya hingga didapatkan $n \in \mathbb{Z}^{+}$sehingga $a \in F_{n}$ dan $n$ ini dijamin ada sebab $a \in \mathbb{L}$. Jadi diperoleh barisan lapangan

$$
\mathbb{Q}=F_{0} \leq F_{1} \leq \cdots \leq F_{n} \leq \mathbb{L} \leq \mathbb{R}
$$

dimana $a \in F_{n}$ dan $\left[F_{i}: F_{i-1}\right]=2$. Penggunaan Dalil 4 secara beruntun memberikan

$$
\left[F_{n}: \mathbb{Q}\right]=\left[F_{n}: F_{n-1}\right] \cdots\left[F_{2}: F_{1}\right]\left[F_{1}: F_{0}\right]=2^{n}
$$

dan karena $\mathbb{Q}(a) \leq F_{n}$, maka $[\mathbb{Q}(a): \mathbb{Q}]=2^{m}$ untuk suatu $m \leq n$.

Dalil 9. Jika $a \in \mathbb{L}$ maka derajat dari polinom minimal untuk a terhadap $\mathbb{Q}$ adalah $2^{m}$ untuk suatu $m \in \mathbb{N}$. Dengan kata lain, jika bilangan riil a adalah akar dari sembarang polinom $p(x) \in \mathbb{Z}[x]$ yang tak tereduksi di $\mathbb{Q}[x]$ dan deg $p$ bukan berupa pangkat dari 2 maka a tidak dapat dilukis

Sedikit kendala dari Dalil di atas adalah bagaimana mengetahui suatu polinom $f$ di $\mathbb{Z}[x]$ tak tereduksi di $\mathbb{Q}[x]$. Bila $\operatorname{deg} f=3$, maka dapat digunakan dalil berikut.

Dalil 10. Misal $f(x)=\sum_{i=0}^{n} a_{i} x^{i} \in \mathbb{Z}[x], \quad a_{i} \neq 0$. Jika $r / s$ adalah akar rasional dari $f(x)=0$ dimana $\operatorname{gcd}(r, s)=1$, maka $r \mid a_{0}$ dan $s \mid a_{n}$. Akibatnya, jika $n=3$ maka $f$ tak tereduksi di $\mathbb{Q}[x]$ bila $f(r / s) \neq 0$ untuk setiap pembagi $r$ dari $a_{0}$ dan $s$ dari $a_{n}$. 


\section{Saiful Amri, Radhiah}

Bukti. Dari $0=f(r / s)=\sum_{i=0}^{n} a_{i} r^{i} / s^{i}$, yaitu dari $0=\sum_{i=0}^{n} a_{i} r^{i} s^{n-i}$, didapat $r \mid a_{0} s^{n}$ dan $s \mid a_{n} r^{n}$. Karena $\operatorname{gcd}(r, s)=1$ maka $r \mid a_{0}$ dan $s \mid a_{n}$.

\section{Jawaban untuk P1 dan P2, keduanya negatif}

Seperti yang sudah dijelaskan sebelumnya, jawaban dari pertanyaan (P1) adalah negatif. Hal ini dibuktikan dengan tidak terlukisnya sudut $20^{\circ}$ yang merupakan kasus khusus ketika $\alpha=60^{\circ}$. Dalil utama dalam tulisan ini adalah Dalil 9. Semua jawaban untuk pertanyaan (P1), (P2) dan keterlukisan dari segi-7 dijawab dengan memanfaatkan dalil ini. Jadi, akan dibuktikan sudut $60^{\circ}$ tidak dapat dibagi tiga dengan memanfaatkan Dalil 9. Supaya dalil tersebut dapat digunakan, perlu dicari $a \in \mathbb{R}$ beserta polinom minimalnya. Pada kasus (P1), a yang dipilih adalah $\cos 20^{\circ}$, karena sudut $20^{\circ}$ dapat dilukis jika dan hanya jika $\cos 20^{\circ} \in \mathbb{L}$ Untuk bukti selengkapnya dapat dilihat pada dalil berikut.

Dalil 11. Sudut $60^{\circ}$ tidak bisa dibagi tiga.

Bukti. Jika sudut $60^{\circ}$ bisa dibagi tiga maka sudut $\theta=20^{\circ}$ dapat dilukis, yang berakibat $a=\cos \theta \in \mathbb{L}$. Tetapi identitas

$$
\frac{1}{2}=\cos 3 \theta=4 \cos ^{3} \theta-3 \cos \theta
$$

menunjukkan bahwa a berupa akar dari $p(x)=8 x^{3}-6 x-1$. Dapat diperiksa dari Dalil 10 bahwa $p(x)$ tak tereduksi di $\mathbb{Q}[x]$, sehingga $a \notin \mathbb{L}$. Oleh karena itu, sudut $20^{\circ}$ tidak dapat dilukis.

Dalil 11 juga mengakibatkan sudut $2^{n} \cdot 20^{\circ}$ tidak dapat dapat dilukis untuk setiap $n \in \mathbb{Z}$. Oleh sebab itu, tidak ada metode untuk membagi tiga sebuah sudut. Akibat lain yang didapat adalah segi-9 tidak dapat dilukis sebab sudut $40^{\circ}$ tidak dapat dilukis.

Jawaban dari pertanyaan (P2) juga negatif. Ketika suatu kubus dengan panjang rusuk $r$ digandakan volumenya, kubus baru memiliki rusuk sepanjang $r \sqrt[3]{2}$. Jadi untuk menjawab (P2) cukup diperiksa apakah $\sqrt[3]{2}$ berada di $\mathbb{L}$ atau tidak. Untuk keperluan ini bilangan $a$ yang dipilih pada kasus (P2) adalah $\sqrt[3]{2}$. Untuk bukti selengkapnya dapat dilihat pada dalil berikut.

Dalil 12. Diberikan suatu kubus, tidak mungkin melukis kubus yang volumenya dua kali dari volume kubus semula.

Bukti. Misal panjang rusuk dari kubus yang diberikan adalah $r$. Jika volumenya dapat digandakan maka $r \sqrt[3]{2} \in \mathbb{L}$ yang berakibat $a=\sqrt[3]{2} \in \mathbb{L}$ Tetapi $a$ berupa akar dari polinom 
$p(x)=x^{3}-2$ yang tak tereduksi di $\mathbb{Q}[x]$. Oleh sebab itu, $a=\sqrt[3]{2} \notin \mathbb{L}$. Jadi, sembarang kubus tidak dapat digandakan volumenya, karena $a=\sqrt[3]{2} \notin \mathbb{L} \square$

\section{Keterlukisan dari segi-7 dan segi-10}

Dalam melukis poligon, suatu cara yang ampuh adalah dengan melukisnya didalam lingkaran satuan pada bidang kompleks $\mathbb{C}$. Diberikan $n \in \mathbb{Z}^{+}$, tidak sulit untuk dibuktikan bahwa

$$
\begin{gathered}
T_{n}=\left\{\operatorname{cis} k \frac{2 \pi}{n}, k=0,1, \cdots, n-1\right\}, \\
\operatorname{cis} \theta \stackrel{\text { def }}{=} \cos \theta+i \sin \theta, \\
i^{2}=-1
\end{gathered}
$$

adalah himpunan yang terdiri dari $n$ unsur yang merupakan titik-titik sudut dari segi-n didalam lingkaran satuan pada bidang $\mathbb{C}$. Dengan sedikit menghitung didapat

$$
(\operatorname{cis} \alpha)(\operatorname{cis} \beta)=\operatorname{cis}(\alpha+\beta)
$$

yang berakibat

$$
(\operatorname{cis} \theta)^{m}=\operatorname{cis} m \theta
$$

dan sekaligus menyimpulkan bahwa $T_{n}$ subgrup siklik berorder $n$ dari $\mathbb{C}^{*}$ yang dibangun oleh $\rho=\operatorname{cis} \frac{2 \pi}{n}$; jadi

$$
T_{n}=\langle\rho\rangle=\left\{\rho^{0}, \rho^{1}, \cdots, \rho^{n-1}\right\}
$$

Berikut sebuah illustrasi untuk $\boldsymbol{n}=\mathbf{1 0}$. Sepuluh buah titik sudutnya adalah $\boldsymbol{A}_{\boldsymbol{j}}=\boldsymbol{\rho}^{\boldsymbol{j}}, \boldsymbol{j}=$ $0,1, \cdots, 9$, dimana $\angle A_{0} O A_{1}=\frac{2 \pi}{10}=36^{\circ}$

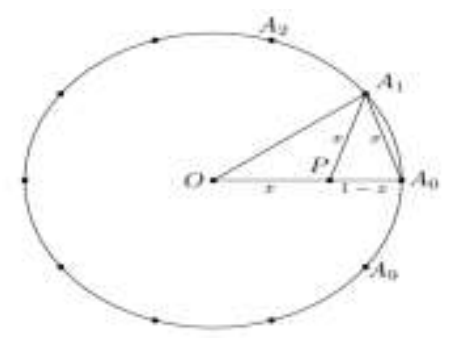

Gambar 2. Ilustrasi untuk segi-10

Dalil 13. Segi-10 dapat dilukis. Akibatnya, segi-5 juga dapat dilukis.

Bukti. Bukti ini dirujuk dari Courant dan Robbins (1996). Tinjau 10 buah titik $\boldsymbol{A}_{\boldsymbol{j}}=$ $\left(\operatorname{cis} \frac{2 \pi}{10}\right)^{j}, j=0, \cdots, 9$, seperti tampak pada gambar. Misal $x=\overline{A_{0} A_{1}}$ Kita tahu $\angle A_{0} A_{1} O=$ 


\section{Saiful Amri, Radhiah}

$\frac{1}{2}\left(180^{\circ}-36^{\circ}\right)=72^{\circ}$, jika $\mathrm{P}$ adalah titik pada $O A_{0}$ sehingga $\overline{A_{1} A_{0}}=\overline{A_{1} P}$, maka $\angle A_{0} A_{1} P=36^{\circ}$ yang berakibat $\triangle A_{0} O A_{1} \approx \Delta P A_{1} A_{0}$ dan $\overline{O P}=x$. Maka $\overline{A_{0} O} \div \overline{A_{1} A_{0}}=$ $\overline{\boldsymbol{P A}} \div \overline{\boldsymbol{P A}}$, yaitu

$$
\frac{1}{x}=\frac{x}{1-x}
$$

atau $x^{2}+x-1=0$ yang memberikan $x=(\sqrt{5}-1) / 2$ dan jelas $x \in \mathbb{L}$.

Dengan menggunakan ide dari bukti di atas, akan dibuktikan bahwa

\section{Dalil 14. Segi-7 tidak bisa dilukis.}

Bukti. Jika segi-7 dapat dilukis maka sudut $\frac{2 \pi}{7}$ bisa dilukis yang berakibat $\cos \frac{2 \pi}{7} \mathrm{di} \mathbb{L}$. Misal $\rho=\operatorname{cis} \frac{2 \pi}{7}$. Karena $\rho^{7}=1$ maka $0=\rho^{7}-1=(\rho-1)\left(\rho^{6}+\rho^{5}+\cdots+\rho+1\right)$

dan karena $\rho-1 \neq 0$ maka

$$
\begin{gathered}
0=1+\rho+\rho^{2}+\rho^{3}+\rho^{4}+\rho^{5}+\rho^{6} \\
=1+\rho+\rho^{2}+\rho^{3}+\rho^{-3}+\rho^{-2}+\rho^{-1} \\
\quad\left(\operatorname{sebab} \rho^{7}=1\right) \\
=\left(\rho+\rho^{-1}\right)^{3}-3\left(\rho+\rho^{-1}\right) \\
+\left(\rho+\rho^{-1}\right)^{2}-2 \\
+\left(\rho+\rho^{-1}\right)+1
\end{gathered}
$$

Ini menyimpulkan bahwa $a=\rho+\rho^{-1}$ berupa akar dari polinom

$$
p(x)=x^{3}+x^{2}-2 x-1 .
$$

Kita tahu $\rho^{-1}=\rho^{6}$ merupakan bayangan dari $\rho$ terhadap sumbu absis, tentu saja $\rho^{6}=$ $\cos \frac{2 \pi}{7}-i \sin \frac{2 \pi}{7}$. Maka $a=\rho+\rho^{6}=2 \cos \frac{2 \pi}{7}$. Karena $p$ irreducible di $\mathbb{Q}[x]$ maka $p(x)$ polinom minimal untuk $a$. Kondisi $\operatorname{deg} p=3$ mengatakan $a \notin \mathbb{L}$ yang berakibat $\frac{a}{2}=$ $\cos \frac{2 \pi}{7} \notin \mathbb{L}$, padahal tadi $\cos \frac{2 \pi}{7} \in \mathbb{L}$.

\section{Kesimpulan}

1. Jika $\alpha=60^{\circ}$, maka sudut $20^{\circ}$ yang merupakan $\frac{1}{3} \alpha$ tidak dapat dilukiskan. 


\section{Saiful Amri, Radhiah}

2. Jika diberikan suatu kubus, maka tidak mungkin melukis kubus yang volumenya dua kali dari volume kubus semula.

3. Poligon segi-7 tidak dapat dilukis, sedangkan segi-10 dapat dilukis, yang mengakibatkan segi-5 juga dapat dilukis.

\section{Referensi}

[1] Courant, R. and Robbins, H., (1996). What is Mathematics? 2nd ed., Oxford University Press, New York.

[2] Herstein, I.N., (1999). Abstract Algebra 3rd ed., John Wiley \& Sons, New York.

[3] Martin, G.E., (1991). Geometric Constructions 2nd ed., Springer-Verlag, New York. 